\title{
Factors influencing the utilization of the public Internet terminal system in two rural communities
}

\author{
A. Coleman \\ Faculty of Information \& Communication Technology \\ Tshwane University of Technology \\ South Africa \\ colemana@tut.ac.za

\section{M.E. Herselman} \\ Faculty of Information \& Communication Technology \\ Tshwane University of Technology \\ South Africa \\ herselmanme@tut.ac.za

\section{S.J. Jacobs} \\ Faculty of Engineering and the Built Environment \\ Tshwane University of Technology \\ South Africa \\ jacobssj@tut.ac.za
}

This research investigated the factors that influence the use of the public Internet terminal (PIT) system in the Taung and Ganyesa communities. The PIT system is placed in many post offices in these communities but the service is not adequately used by these rural community members. The overall objective of this study was to investigate, develop and recommend a solution for providing the rural communities of Taung and Gyanesa with a simple and effective way to access and utilize the PIT service and the information on it. A case study approach was used for the purpose of this study which gathered a number of findings, including lack of awareness of PIT services, lack of computer skills and confidence, and fear of technology. Other findings were the overloading of information on the PIT, use of language (not the mother tongue), and the slow response of the PIT system. The findings from this study led to some recommendations and a model for PIT use inr rural communities.

Key words: Information kiosk, public Internet terminals (PIT), information and communication technology (ICT) provision, rural communities

Received: 19 September 2007; accepted 15 February 2008

\section{Contents}

1. Introduction and orientation 
2. Problem statement

3. Defining the types of information kiosks

4. Factors hampering the use of information on Internet kiosks

5. Methodology

6. Research findings

7. Recommendations

8. Conclusion

9. References

\section{Introduction and orientation}

Providing information to rural communities in Africa for rural development can best be achieved through information technologies, especially those of electronic network and digital storage (CTA 1996). South Africa's rural communities are no exception. The World Bank Development Report (2000/2001) propagates that information technology (IT) can reduce poverty in Africa by increasing opportunities and enhancing empowerment of the rural poor people.

To move and implement this concept of the provision of information and communication technology (ICT) for rural development, the South African government has enshrined in its ICT Charter (2004) the attempt to ensure that all its citizens have the opportunity to access and effectively use ICT. According to Jacobs and Herselman (2006), this will enable citizens to participate fully in the educational, social and economic activities and the democratic process in South Africa. To achieve this, the South African government, through the Department of Information and Communication (DoC), in partnership with the South Africa Post Office (SAPO), has rolled out public Internet terminals (PIT) in many post offices as part of the Department of Communication's national projects (DoC 2003). The fundamental objective of PIT is to create a communication infrastructure through which the public will have access to government information and services. The public will also be empowered to have electronic access to information and communication via electronic mail.

The conceptualization of the PIT project was based on the pursuit of the Department of Communication's mission statement, which is 'to strive towards a universal service to enable ordinary people to have access, not to traditional media, but also the convenience of Information Technology' (DoC 2003). According to the ICT Charter (2004), the provision of IT services to the rural communities will create a flourishing information society that will improve the quality of life of South Africans and contribute to the economic growth of the nation. However the rural communities of Taung and Gyanesa do not effectively make use of the PIT system.

The main focus of this research was to investigate, develop and recommend a solution for providing the rural communities of Taung and Gyanesa with a simple and effective way to access and utilize the PIT services and the information that are provided on the government Website on the PIT.

\section{Problem statement}

Owing to the growing popularity of the Internet, the government together with the SAPO has invested a substantial amount of money to set up about 700 PIT workstations (DoC 2003) at various post offices in many rural communities. These rural communities include Taung and 
Ganyesa in the Bophirima Region of the North West Province in South Africa.

Despite the infrastructural investment of 700 PIT workstations (DoC 2003) that have been set up in various rural post offices like Taung and Ganyesa, the problem is that people in these rural areas do not effectively use the PIT services for information and the other services that are intended to be provided by the PIT system. As these rural communities do not use the services of ICT effectively, it can create a technological chasm (Raab, Bellamy, Taylor, Dutton and Peltu 1996). With this background, therefore, the research question was:

What are the factors influencing the use of the PIT system for disseminating government services and information?

\section{Defining the types of information kiosks}

The Department of Communications (DoC 2003) defines PIT as a public Internet terminal, that provides services such as government information, educational services, e-mails, Internet browsing and business transactions. As reiterated by Matsepe-Casaburri (2000) the links to the government's Website provide information on aspects of regulation, legislation, welfare, support grants and rebates to the South African people. Interactive directories of various tertiary institutions are also available.

Morris, Sanders, Gilman, Adelson and Smith (1995) state that a kiosk is a small rugged stand-alone structure that is often used as a news stand or band stand for commercial enterprise. Rowly (2000) defines a kiosk as a workstation that is specifically designed for public accessibility and it may stand alone or be networked to a larger computer system. Furthermore, Karcher (2001) defines an information or Internet kiosk as a stationary personal computer (PC) that is designed for public use with the unique requirements of applications, software, hardware and connectivity for the users in a particular location. In this research study, PIT was defined as a stand-alone PC, which is set up in a public place to provide information and Internet services.

Considering information kiosks in more detail, Castells (1998) categorized kiosks according to their transactional power and information availability. Four types or categories of kiosks are mentioned:

Type 1: Information kiosks with low transaction power and low information availability such as the kiosks at airports, railway and bus stations, which are used for purchasing tickets. Type 2: Information kiosks with high transaction power and low information availability such as the kiosks at libraries that are used for the self-scanning of books.

Type 3: Information kiosks with low transaction power and high information availability such as the kiosks at railway and bus stations that are used for finding information on timetables, and the kiosks at car dealers that are used for visualizing a particular car. Type 4: Information kiosks with high transaction power and high information availability such as the kiosks that allow citizens to pay their taxes or access public information.

Moerloose, Antico, Lindgreen and Palmer (2005) indicate that other types of information kiosks have appeared since then. Rowley and Slack (2003) suggest that the following dimensions of an information kiosk are useful:

- Information provision and promotion

- Information exchange between users and the kiosk

- Commerce and sales

- Strength of customer-retailer relationship that the kiosk supports. 
Rowley and Slack (2003) argue that the environment, users, tasks and technology should be considered in the design of public access systems. It has been noted that information kiosks have received little media, professional or academic attention (Rowley and Slack 2003; Nicholas, Huntington and Williams 2001). Nevertheless, over the past few years information kiosks have become widespread as an interactive means of providing information to the public (Hariri, Goodyear, Anderson and Meyer 1997; Rowley 2000; Rowley and Slack 2002).

The governments of many African countries are therefore exploiting the advantages of information and Internet kiosk type four to provide information to their rural communities. However, it is important that rural communities use these IT facilities adequately.

top

\section{Factors hampering the use of information on Internet kiosks}

Cecchini and Scott (2003:73) identify three critical elements of poverty reduction efforts, namely opportunity, empowerment and security, and further state that ICT is the vehicle for achieving this poverty reduction. They state that the experiences from rural India show that ICT, through the use of information kiosks, can enhance poor people's opportunities to access government services and other useful information.

However, there are factors that hamper the use of these information kiosks in our rural areas. These include issues such as socio-economic factors, the user interface, the conceptual model of users and the local acceptability of ICT.

Socio-economic factors: Unfortunately information and communication appear to be both unifying and divisive. In other words, despite its offered advantages, the use of ICT by governments will exclude those who lack access to these services and information or those who do not use them effectively. This issue is often referred to as the 'digital divide' (Raab et al. 1996; Civille 1995; Jacobs and Herselman 2006). However, the significance of this term is still controversial and there are some researchers who assert that an information underclass cannot be defined in terms of 'have and have-not' access (Castells 1998) without including both socio-economic factors such as low income, low level of education and lack of technology skills, and socio-personal factors such as low level of awareness, interest and acceptance of ICT's usage (Foley, Alfonso and Ghani 2002).

The ScottishExecutives(2001) list the following factors as some of the main contributors to digital exclusion:

- Perceived or actual cost of personal computers, other equipment and Web-related phone calls

- Access, as the lack of nearby or affordable facilities providing access to Web-ICTs and to build the skills and awareness to use them

- Skills that include the lack of literacy, numeric and ICT skills

- Cultural issues, which are the lack of critical mass of PC users among community, friends and family

- Personal factors, which are the lack of confidence, credit card or bank account, fear of technology, no interest in the Internet and physical difficulties such as poor eyesight, or minimal dexterity and co-ordination.

Navigation constraints associated with user interface: One of the frequently addressed issues concerning accessibility of e-services and information on the Internet is the user's lack of awareness about where the desired information or services are stored on the Web (Santosa 
2003). In other words, when visiting a Website, an individual user is presented with a fixed set of choices. Raymond, Giovanni, Christine and Victor, (1997:138) indicate that it is only by stepping through the offered choices and conforming to the prescribed organization of the $\mathrm{Wb}$ that the user can reach the document he or she desires. This is a navigation problem and therefore requires computer skills and experience (Darken, Allard and Achille 1999).

Challenges associated with the conceptual model of users: Norman (1998) points out that the use of any device or tool is underlined by, among other things, the mental or conceptual model of the user. Norman (1998:561) defines a mental model as the information a person has stored in memory about a situation, an event, or a procedure, and this, according to Norman (1998:17), is formed through experience, training and instruction. Norman (1998:189) further explains that the operation of any device, whether it is a can opener, a power-generating plant or a computer system, is learned more readily and the problems are tracked down more accurately and easily if the user has a good conceptual model about that device. Therefore, as Santosa (2003) points out, in an unfamiliar environment such as a Website, users are confronted with a lack of a plan of action which will enable them to navigate through the Website. Consequently, to resolve the problem of navigation difficulty and way-finding in the Web environment, the user should possess an appropriate conceptual model of the Website. To this end, it requires that the principle of operation be observable, that all actions are consistent with the conceptual mode and that the visible parts of the device reflect the current state of the device in a way that is consistent with the model (Norman 1998:189). Therefore, to ease the mental activities of the user, colour, font and graphics must be used as way-finding cues (Ling and Van Schaick 2002). Figure 1 illustrates the screen of a PIT system with fonts, graphics and colour as way-finding cues.

Figure 1 Screen of PIT (DoC 2003)

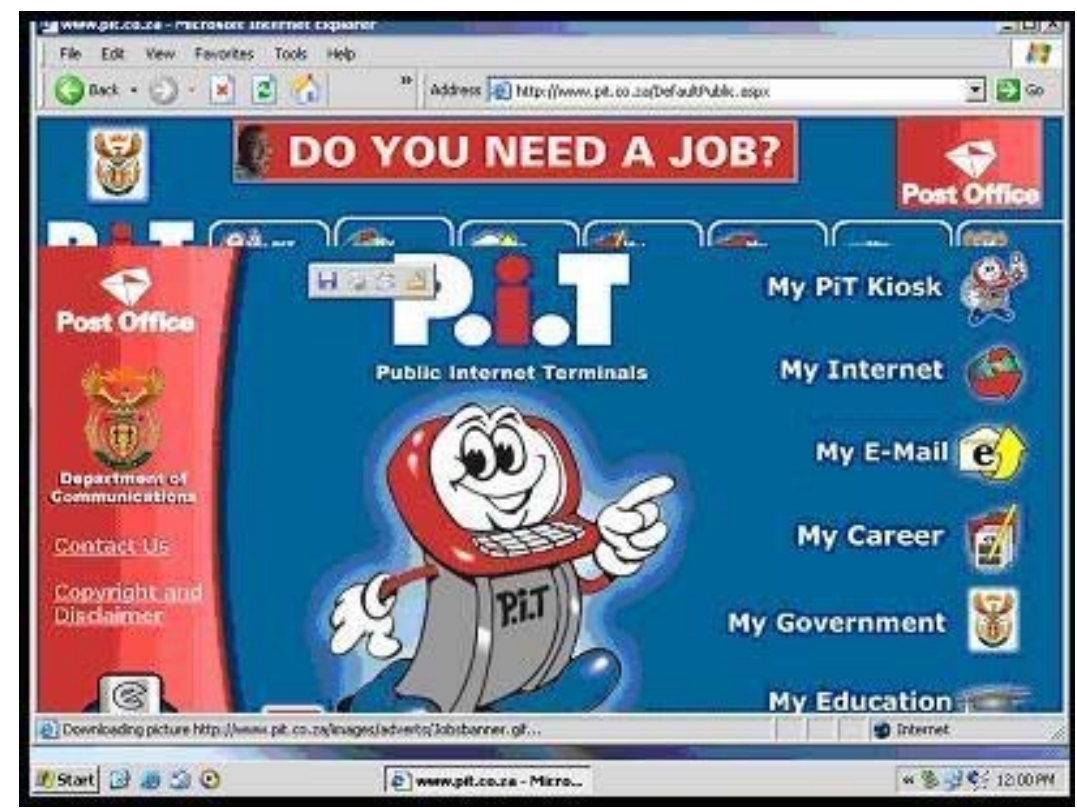

Challenges associated with local acceptability of ICT: Nielson (1993) defines acceptability in terms of both practical and social acceptability as illustrated in Figure 2. Social acceptability is implicitly concerned with whether or not a system's intended users and other stakeholders think that the system is a legitimate, worthwhile or ethical use of resources, regardless of how well it works by other criteria (Whyte and Macintosh 2003:17). Practical acceptability, among other things, is defined by Nielson (1993) in terms of utility, usability, cost, compatibility and reliability, as illustrated in Figure 2 below.

Figure 2 Acceptability structure (Nielsen 1993:25) 


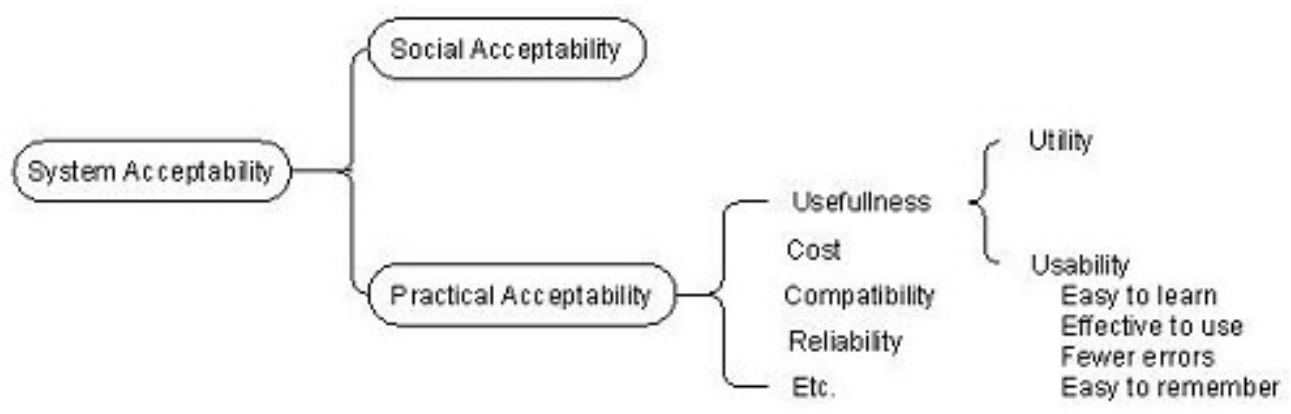

According to Cecchni (2001), the involvement of local communities in any communitybased ICT project fosters the success and resilience of that ICT project. Cecchni (2001) further states that outside control and a top-down approach, on the other hand, often result in a waste of resources in the initial period of the project and therefore endanger the future sustainability of the project. A typical example given by Cecchni (2001) is the Raj Nidhi state sponsored e-government project which failed, despite the fact that the software was easy to use and it was also in the local Hindi language. This was because of the extremely centralized planning that did not take the local communities and their conditions into consideration (Cecchni 2001).

Conradie and Jacobs (2003) explain that the major challenge that has to be addressed is a social challenge, which has to do with developers bringing ICT into a rural area without adequate consultation with the local communities with regard to local needs that the technology should address. A technology push development strategy, which offers an ICT solution without taking into account the local needs of the community, is bound to fail.

Jacobs and Herselman (2006) summarize this by stating that the value of ICT should be found in the community-owned activities and community space where issues of importance to the community are addressed.

\section{Methodology}

To address the purpose of this study without sacrificing the relevance, a qualitative research approach with a multiple case study as the method was selected. Olivier (2004:100) states that the ability to collect a variety of information from a case is, in fact, one of the major strengths of a case study method. Based on the research purpose, which was to determine the social situation of the participants, a qualitative approach was used in this study.

The data collection was done through both primary and secondary sources. The primary data source included participants from each rural community, while the secondary data source covered different sources such as the literature review, which provided an essential preparation for the interviews and the questionnaire. Moreover, the secondary data source assisted to crosscheck official information and supported the exploration of participants' responses during the interviews.

The main data collection techniques that were applied in this study included the use of observation, questionnaires and semi-structured interviews. Purposive sampling (Leedy 1992:55) was applied to select participants for this study from both Taung and Ganyesa as rural areas in the Bophirima Region of the North West Province. Taung is situated to the south of Vryburg, which is the regional centre of the area while Ganyesa is located to the north of Vryburg. The total number of respondents was reached heuristically. This means the participants were selected from a population group of teachers, nurses, business people, 
students and community leaders. The participants were males and females between the ages of 15 and 50 years old. All interviews were transcribed in Microsoft Word format and extensive notes were taken. Interview transcripts and notes were analysed systematically through iterative and repeated reading of the transcripts. This made it possible to gain an increasingly profound understanding of each interviewee's viewpoints and perspectives.

Table 1 represents the data collection instruments and the number of people who participated from each community.

Table 1 Data collection instruments and participants

\begin{tabular}{|l|l|l|l|}
\hline $\begin{array}{l}\text { Data collection } \\
\text { instruments }\end{array}$ & Taung & Ganyesa & Number \\
\hline Observation & 5 Participants & 5 Participants & $N=10$ \\
\hline Questionnaire & 5 Participants & 5 Participants & $N=10$ \\
\hline Interviews & 5 Participants & 5 Participants & $N=10$ \\
\hline
\end{tabular}

Each participant was given 20 minutes to use the PIT. A test was conducted whereby each participant was expected to perform a particular task on the PIT within that period of 20 minutes. The task stated below was given to the participants to perform:

'Find a government Website on AIDS and request for a support centre to be built in your community.'

The test was monitored in a form of direct observation by the researcher and video and audio recording supplemented it. A microphone was placed at the front of the computer to capture the user's voice and comments as he or she performed the task. The focus of the camera was on the monitor of the test PIT computer. The direct observation was supplemented by brief handwritten notes by the researcher, and the video recorder was used for retrospective analysing and for reviewing the gathered information (Edwards and Westgate 1987). To reduce anxiety among the participants, the participants were informed about the purpose of the research and the tasks were performed in an informal relaxed atmosphere.

By adopting a task-based approach in gathering the data, the main focus of the study was to determine the factors which influence the communities not to use the PIT system for government services and information.

\section{Research findings}

The following were found as factors that influenced the community users when engaging with the PIT system:

- Overload of information on the Web of the PIT system (73\%)

- The absence of an appropriate conceptual model of the participants $(69 \%)$

- The use of language that was unfamiliar (not the mother tongue) on the Web (78\%)

- The slow response of the PIT system (70\%)

- Lack of awareness of the PIT services to the community people.

The findings confirmed that $50 \%$ of the participants visited their local post office three times or more per week. However, $70 \%$ of the participants had never used the PIT system before. 
Figure 3 illustrates the percentage of participants who visited their local post office once, twice or three times per week and the frequency of PIT usage (as was monitored over a period of three months).

Figure 3 Participants' visits to the local post office per week
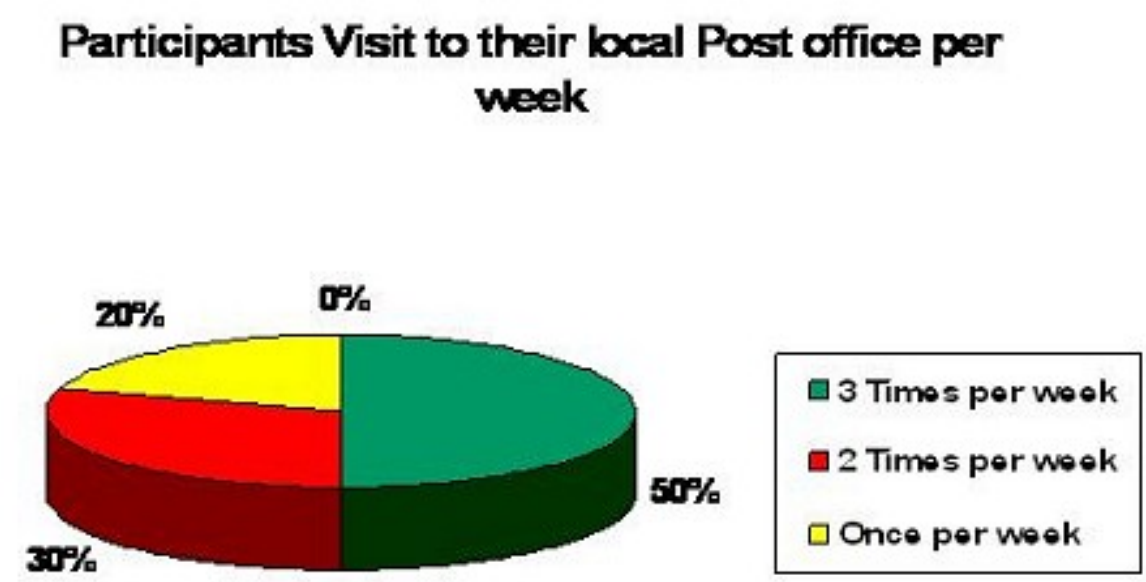

Furthermore, participants indicated in their responses during the interviews that the major factor hampering them from using the PIT system was the lack of awareness of PIT services at their local post office. The lack of computer skills and confidence of the people were also cited as hampering factors as well as the fear of technology.

The following were stated by participants as some of the benefits that the PIT system can bring to the community.

- Assist the community members to search for jobs

- Link the community to the outside world

- Help their children's education

- Help them obtain relevant government information.

The responses from the participants show a positive social acceptance of the PIT system. However, the problems stated above hamper the use of the PIT system to the full benefit of the community. All these findings are supported by previous literature discussions.

\section{Recommendations}

The following recommendations should assist the participants of both Taung and Ganyesa to effectively utilize the services of the PIT system in their local communities:

- The use of human assistance for PIT users in Taung and Ganyesa: It was observed that the participants could not operate the PIT system when given the task to use the PIT machine. It is therefore recommended that the postmasters of both Taung and Ganyesa hire people who have the relevant skills who will sit by the PIT system at the post offices to assist clients with information on how to operate the PIT system.

- Use of the local Setswana language and information for the rural communities: It was also noted that the participants from both Taung and Ganyesa could not understand the language on the Web of the PIT system (78\%). It is therefore recommended that information stored on the server be made more meaningful and 
relevant to the local users of the PIT system. Therefore the Web application must have the alternative local language of Setswana and be visually oriented as far as possible. Information stored in the server must be meaningful and relevant to the local community.

- Create the awareness of PIT among the local community of Taung and Ganyesa: One of the major findings was the lack of awareness of PIT services among the participants of Taung and Ganyesa. It is therefore important that the availability or existence of the PIT system and its services and usefulness be communicated or marketed to the community members. This can be done through various media and channels such as local radio stations, local tribal meetings and other workshops in a bid to increase the visibility and awareness of the PIT system. Attempts can also be made for the chiefs to allow representatives from the Department of Communication and the South African Post Office to give presentations during traditional tribal meetings on the usefulness of PIT and the services that the PIT system can offer to the local community.

- Voluntary training of community members of Taung and Ganyesa in the use of PIT: Another problem that became apparent during the study was the inability of the participants of both Taung and Ganyesa to operate the PIT machine. This was due to the lack of ICT skills of the participants. Therefore, it is recommended that voluntary training be given to the local community once every month to expose them to the use of PIT and its benefits. This can be done by the appointment of a trained human assistant or any trained computer user.

- Promote local ownership of the PIT system for users of Taung and Ganyesa: Participants indicated their acceptance of the PIT system in both the Taung and Ganyesa communities. For them to be effectively involved in the use of the PIT system, it is recommended that any new application or program that is introduced on the PIT system be done in collaboration with the local community through the community leaders. It is equally recommended that the programs must reflect the needs of the communities. Communities such as Taung and Ganyesa will gladly accept programs that give them information on their social grants and the days of payment of such grants, the payment of electricity and water bills and the payment of monthly account instalments.

\section{Conclusion}

The research results indicate that a need exist for the PIT systems to be effectively used to allow communities to access governmental services and information. It is therefore imperative that local communities be made aware of services and the benefits of the PIT system through their local chiefs, municipalities and community radio stations.

The recommendations, namely of a human assistant, the use of the local or mother tongue, creating awareness, providing voluntary training and promoting local ownership, need careful consideration if the PIT system is to be successfully and effectively used in all rural communities.

\section{References}

Castells, M. 1998. The information age 3: end of millennium. Blackwell, Oxford: 92-95.

Cecchini, S. 2001. Back to office report: information and communication technology for 
poverty reduction in rural India Mimeo. World Bank: Washington D.C. [Online]. Available http://www.developmentgateway.org (accessed 15 October 2007).

Cecchini, S. and Scot, C. 2003. Can information and communication technology application contribute to poverty reduction? Lesson from Rural India. Santiago: ECLAC, United Nations Casilla 179-D.

Civille, R.1995. The Internet and the poor, in public access to the Internet. US: MIT Press Cambridge Mass.

Conradie, D.P. and Jacobs, S.J. 2003. Challenges encountered when using ICTs (information and communication technologies) in support of development in rural African communities. Engineering Management: 30-33.

CTA.1996. The role of information for rural development in ACP countries: review and perspective. Proceedings of an international seminar. Wageningen CTA: 207.

Darken, R.P., Allard, T. and Achille, L.B.1999. A theoretical model of way-finding in virtually environment: proposal strategies for navigational aiding. Presence (8, 9):671-685.

Department of Communication (DoC). 2003. Public Internet terminals (PIT). [Online]. Available WWW: http://www.doc.gov.za/PIT_Sumy.htm (Accessed 18 August 2006).

Edwards, A.D. and Westgate, D.P.G.1987. Investigating classroom talk. Lewes: Flamer Press.

Foley, P., Alfonso, X. and Ghani, S. 2002. The Digital Divide in a World City. Published by the Greater London Authority, London. [Online]. Available WWW:

http://www.casa.ucl.uk/cyberspace/london digital divide.pdf (Accessed 13 October 2006).

Hariri, S., Goodyear, L., Anderson, C. and Meyer, J. 1997. Cardio pharm: interactive multimedia health promotion software for community pharmacy. Nutrition and Food science 2(3):71-5.

ICT Charter. 2004. ICT empowerment charter: working group research unit. [Online]. Available WWW: http://www.ictcharter.org.za (Accessed 13 October 2006).

Jacobs, S.J. and Herselman, M.E. 2006. Information access for development: a case study at a rural community centre in South Africa. Issues in Informing Science and Information Technology 3.

Karcher, M.D. 2001. Public Internet kiosks offer Web access. Leatherneck. Quantico 84 (11):80-83.

Leedy, P.D. 1992. Practical research: planning and design. New Jersey: Prentice Hall.

Ling, J. and Van Schaik, P. 2002. The effect of text and background colour on visual search of web pages. Display 23:223-230.

Matsepe-Casaburri, I. 2000. Speech by communications minister at the official opening of the Tshwane Mail Centre in Pretoria. [Online]. Available WWW: http://www.polity.org.za/html/govdocs/speeches/2000/sp0904.html (Accessed: 15 November 2006). 
Moerloose, C., Antico, M., Lindgreen, A. and Palmer, R., 2005. Information kiosk; the case of Belgian retail sector. International Journal of Retail \& Distribution Management, 33:6-7.

Morris, G., Sanders, T., Gilman, A., Adelson, S.J. and Smith, S. 1995. Kiosks: technological overview. Los Alamos CIC-3: LA-UR-95-1672.

Nicholas, D., Huntington, P. and Williams, P. 2001. Establishing metrics for the evaluation of touch screen kiosks. Journal of Information Science, 27(26):1-71.

Nielson, J. 1993. Usability engineering. Cambridge MA :Academic Press.

Norman, D.A. 1998. The psychology of everyday things. NY: Basic Books.

Olivier, M.S. 2004. Information technology research: a practical guide for computer science and informatics. Pretoria:Van Schaik Publishers.

Raab, C., Bellamy, C., Taylor, J., Dutton, W.H. and Peltu, M. 1996. The information policy: electronic democracy. Privacy and surveillance in information and communication technologies: vision and realities. Oxford: Oxford University Press.

Raymond, L., Giovanni, F., Christine, P. and Victor, Z. 1997. Webgalaxy: beyond point and click - a conversational interface to a browser. Computer Network and ISDN system 29:1385-1393.

Rowley, J. and Slack, F. 2003. Designing public access systems. Gower: Aldershot.

Rowly, J. 2000 . Loyalty kiosks: making loyalty cards work. British Food Journal 102 (5):390-397.

Santosa, P.I. 2003. Observing a user's mental model of an information Website. Ninth American Conference on Information Systems: 2223-2230. [Online]. Available WWW http://galletta.business.pitt.edu/amcis2003/index.htm (Accessed 18 September 2006).

Scottish Executives. 2001. Digital inclusion: connecting Scotland's people. [Online]. Available WWW: http://www.scotland.gov.uk/library3/enterprise/dics-00ASP (Accessed 17 October 2006).

Whyte, A. and Macintosh, A. 2003. Demonstration, analysis and assessment report. AVANTI External Report: 17.

World Bank Development Report. 2000/2001. Attacking poverty. New York:Oxford University Press. [Online]. Available WWW: http://www.worldbank.org/poverty/wdrpoverty (Accessed 18 August 2006). 
ISSN 1560-683X

Published by InterWord Communications for Department of Information and Knowledge Management, University of Johannesburg 